\title{
Efeitos do extrato de própolis e do óleo de melaleuca na formação do biofilme e na desmineralização dental: estudo in situ
}

\author{
Effects of propolis extract and tea tree oil on biofilm formation \\ and dental demineralization: in situ study
}

Rosiane Stefanello*

Fábio Hermann Coelho de Souza**

Gabriel Dias de Castro***

\section{Resumo}

Objetivo: avaliar os efeitos de soluções naturais na formação do biofilme e na prevenção da desmineralização dos dentes. Sujeitos e método: realizou-se um estudo piloto, in situ, com 12 voluntários, que utilizaram dispositivos de acrílico removível, contendo 4 blocos de dente cada. Os blocos de dente foram submetidos ao desafio cariogênico, quatro vezes ao dia, e testados com uma solução experimental, duas vezes ao dia, durante 14 dias. A amostra foi dividida em quatro grupos, com três indivíduos em cada grupo, os quais testaram as seguintes soluções: soro fisiológico (Grupo 1), clorexidina 0,12\% (Grupo 2), óleo de melaleuca 0,2\% (Grupo 3) e extrato de própolis 30\% (Grupo 4). Ao final de 14 dias o biofilme formado foi coletado e semeado em três meios de cultura diferentes, os blocos de dente foram pesados em balança de precisão e testados quanto à microdureza superficial. Resultados: os resultados mostraram que houve um grande crescimento microbiano em todos os meios de cultura; houve uma tendência de perda de peso mineral nos blocos dos Grupos 1, 2 e 3, enquanto o grupo 4 mostrou uma tendência de ganho de peso. Na análise da microdureza superficial, observou-se uma tendência de menor resistência da dentina após o desafio cariogênico, em todos os grupos, comparados ao grupo controle que não foi submetido ao desafio cariogênico. Conclusão: o óleo de Melaleuca $0,2 \%$ não influenciou na formação de placa, na dureza superficial e no peso dos blocos, enquanto que o extrato de própolis mostrou uma tendência de interferir na formação de placa e no peso mineral dos dentes.

Palavras-chave: Óleo de Melaleuca. Própolis. Biofilme dentário. Produtos naturais.

\section{Introdução}

A cárie dental consiste em uma doença crônica, infecciosa e de alta prevalência, que provoca a desmineralização irreversível dos tecidos mineralizados dos dentes. Também se caracteriza como um processo multifatorial, visto que exige a interação de diversos fatores para que a doença se estabeleça $\mathrm{a}^{1,2}$.

Pode-se dizer que enquanto houver um equilíbrio no processo de desmineralização e remineralização o indivíduo está isento de cárie, porém não está imune. Se esse equilíbrio for quebrado, haverá uma situação de cariogenicidade que pode evoluir para o aparecimento da mancha branca ativa e, futuramente, a cavitação do dente. O desafio cariogênico pode ser intensificado pelo aumento na freqüência de ingestão de sacarose e pelo aumento no intervalo de tempo para o controle mecânico periódico do biofilme microbiano ${ }^{3}$.

O controle mecânico do biofilme promove uma desorganização da massa bacteriana presente no dente e, ainda hoje, é a forma mais segura para a conservação da saúde bucal, prevenindo o processo da cárie e de outras doenças, como a gengivite. Contudo, pela alta prevalência dessas doenças na população, entende-se que muitos indivíduos apresentam deficiência no padrão e na qualidade de seu hábito de higiene oral. Logo, o interesse pelo controle químico do biofilme dental vem sendo bastante estudado por caracterizar-se como uma alternativa que se

Acadêmica do Curso de Odontologia da ULBRA - Campus Cachoeira do Sul, RS, Brasil.

Doutor em Dentística pela UFPel. Professor adjunto do curso de Odontologia da UFRGS, RS, Brasil.

Especialista e Mestre em Periodontia pela UFRGS. Professor adjunto do curso de Odontologia da ULBRA - Campus Cachoeira do Sul, RS, Brasil. 
justifica por duas razões: a primeira, pela ação antimicrobiana de substâncias que podem eliminar/combater os agentes etiológicos das doenças cárie e periodontal; a segunda, pelo efeito benéfico dos antissépticos bucais como coadjuvantes ou substitutivos ao controle mecânico do biofilme, para pessoas com dificuldade motora de realizar uma boa higiene ${ }^{2,4,5}$.

A investigação de produtos para o controle químico do biofilme microbiano supragengival tem o intuito de melhorar o controle de placa, sem depender exclusivamente do controle mecânico ${ }^{6}$. Nesse sentido, a clorexidina é considerada o padrão-ouro nas pesquisas de agentes antissépticos bucais, capaz de ser utilizada em substituição à escovação mecânica, no entanto apresenta inúmeros efeitos colaterais se usada por períodos prolongados ${ }^{2,7}$, como manchamento dentário e de restaurações, alteração de paladar e maior formação de tártaro.

A medicina popular existe há milhares de anos e é utilizada, de maneira empírica, por muitas pessoas. Nesse sentido, vários produtos naturais têm sido testados e cada vez mais são utilizados para o tratamento de doenças, a fim de reduzir as desvantagens trazidas pelo uso crônico de medicamentos alopáticos. Preparações com diferentes finalidades podem ser extraídas de plantas, de animais, ou de vegetais e, entre eles, destacam-se a solução de própolis e os óleos essenciais ${ }^{7,8}$. Entre os óleos essenciais de produtos naturais, o Leptospermum scoparium, a Melaleuca alternifólia, o Eucalyptus radiata, a Lavandula officinali, o Ocimum basilicum, o Thymus vulgaris, o Cinnamomum cassia, o Allium sativum, o Euterpe oleracea e o Rosmarinus officinalis demonstraram que podem inibir a formação do biofilme, agindo na adesão dos microrganismos à superfície dental, e não apresentando efeitos citotóxicos para as células humanas. . $^{8,9,10}$.

As pesquisas relacionadas aos produtos naturais cresceram significantemente frente ao anseio pela busca por produtos biocompatíveis, com menor toxicidade, maior atividade farmacológica e com custo mais acessível à população. Estudos mostram que preparações com plantas podem ser utilizadas para inibir o crescimento bacteriano, a aderência nas superfícies dentais e para reduzir a produção de ácidos e polissacarídeos extracelulares ${ }^{10}$.

$\mathrm{Na}$ odontologia, apesar do uso da fitoterapia ser milenar, a utilização de plantas medicinais para tratar doenças bucais ou para tratar doenças sistêmicas com manifestações bucais ainda é pouco explorada. Por isso, é imprescindível a exploração científica dos produtos fitoterápicos para melhorar o conhecimento destas substâncias e vislumbrar suas magníficas propriedades destinadas a cada área de atuação.

O objetivo desta investigação foi avaliar o efeito do extrato de própolis $30 \%$ (Apis mellifera) e do óleo de Melaleuca 0,2\% (Melaleuca alternifólia) sobre a formação do biofilme dental e na manutenção dos níveis minerais, frente ao desafio cariogênico, em um modelo experimental in situ.

\section{Sujeitos e método}

\section{Aspectos éticos}

O presente trabalho foi aprovado pelo Comitê de Ética em Pesquisa em Seres Humanos (CEP) da Universidade Luterana do Brasil (ULBRA), em Canoas, sob o número 1.294.015. Todos os voluntários assinaram o termo de consentimento livre e esclarecido, antes de iniciar o período experimental.

\section{Desenho experimental}

Este estudo caracterizou-se de um ensaio clínico randomizado em um modelo de estudo in situ.

\section{Seleção da amostra}

Foram selecionados 12 voluntários para participar do estudo ( 3 do gênero masculino e 9 do gênero feminino), com idades entre 19 e 26 anos e com boa saúde bucal. Cada indivíduo utilizou um dispositivo de acrílico intra-oral palatino, contendo 4 blocos de esmalte e dentina cada, alojados na região de pré-molares e molares, durante um período de 14 dias (Figura 01).

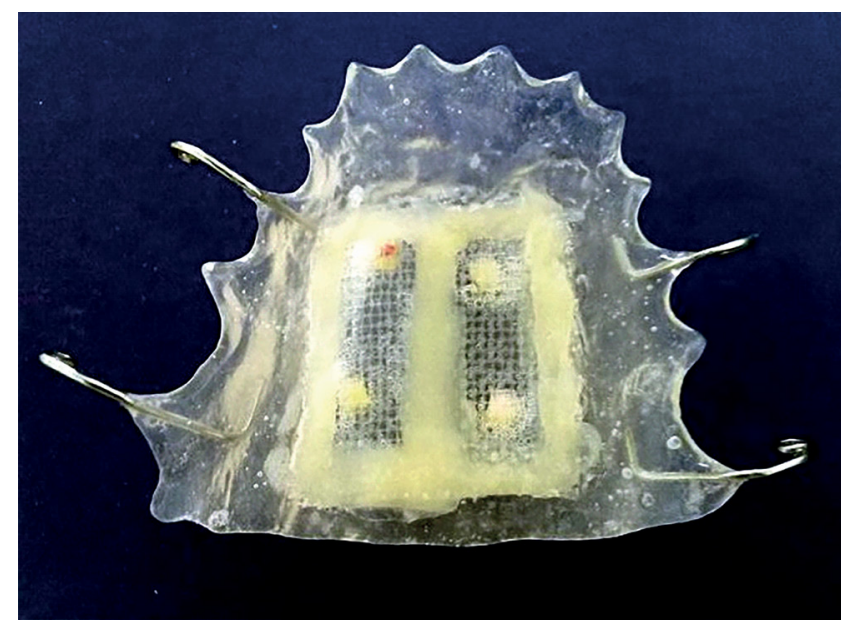

Figura 1 - Vista do dispositivo de acrílico intra-oral que cada voluntário utilizou durante o período experimental.

\section{Critérios de exclusão}

Foram excluídos da amostra indivíduos fumantes, usuários de antibióticos nos últimos 3 meses ou no momento do estudo, quem estivesse em dieta nutricional, usuários de inibidores de apetite, indivíduos com aparelhos ortodônticos fixos ou móveis e usuários de prótese parcial removível ou prótese total. 


\section{Período experimental}

Os voluntários selecionados foram avaliados clinicamente, pelo pesquisador (RS), por meio dos exames de Índice de Placa Visível (IPV), Índice de Sangramento Gengival (ISG) e Fator Retentivo de Placa (FRP). Após, receberam Raspagem Alisamento e Polimento (RAP) e remoção dos FRP, conforme as necessidades individuais.

Os voluntários foram divididos, aleatoriamente, em 4 grupos de tratamento, com 3 indivíduos em cada grupo. Para simular o desafio cariogênico utilizou-se sacarose $20 \%$ em todos os grupos gotejada $4 \mathrm{x}$ ao dia pelo voluntário (às $8,12,16$ e 20 horas) e, além disso, cada grupo testou uma substância a fim de inibir o crescimento de biofilme gotejada duas vezes ao dia, de manhã e de noite (às 7 e 21 horas). No grupo I, utilizou-se soro fisiológico (controle negativo); no Grupo II, Clorexidina a $0,12 \%$ (controle positivo -PerioGard ${ }^{\circledR}$,Colgate-Palmolive,São Paulo/ Brasil); no Grupo III, óleo de Melaleuca alternifólia 0,2\% (Dermapele, Santa Maia/Brasil) e no Grupo IV, extrato alcoólico de própolis $30 \%$ (Arte Nativa ${ }^{\circledR}$, São José da Lapa/Brasil) ${ }^{11,12,13}$.

Nos períodos pré determinados, cada voluntário deveria pingar uma gota da solução destinada, em cada bloco dental. Após a aplicação, cada indivíduo foi instruído a aguardar cinco minutos para reinserir o aparelho em boca. Os voluntários foram orientados a não alterar seus hábitos de higiene e de dieta, durante as semanas do estudo. As orientações foram passadas verbalmente e por escrito.

Durante a fase experimental, os voluntários usaram o aparelho por 14 dias, inclusive durante a noite. A remoção dos aparelhos só deveria ser feita durante a higiene bucal e durante as refeições.

Após duas semanas, os dispositivos foram recolhidos e o biofilme formado sobre os blocos de dente, do lado esquerdo do aparelho, foi coletado para avaliação microbiológica. $\mathrm{O}$ bloco anterior, do lado esquerdo, foi escolhido para a aferição da microdureza. Além disso, todos os blocos dentais foram pesados, antes e depois do período experimental, para avaliação do ganho ou perda mineral.

\section{Preparação dos blocos de dente}

Para a confecção dos 12 dispositivos intra-orais, 48 blocos de dente foram utilizados (4 blocos em cada aparelho). Os dentes eram de origem humana, extraídos por indicação ortodôntica ou outro motivo (pré-molares e terceiros molares). Os dentes não apresentavam cavidade de cárie, mancha branca ativa ou defeitos no esmalte. Eles foram esterilizados em solução de ácido peracético $0,2 \%$ imersos durante 20 minutos $^{14}$. Os dentes foram seccionados com disco de acabamento para porcelana (Dentorium, exportado por Labordental Ltda, São Paulo/ Brasil) em peça reta com refrigeração. $\mathrm{O}$ corte deu-se no sulco principal (no sentido mesiodistal) e entre as cúspides (no sentido vestíbulolingual). As dimensões dos blocos, contendo esmalte e dentina, foram de $2 \times 2 \times 2 \mathrm{~mm}$, averiguadas com paquímetro manual (Vonder ${ }^{\circledR}$, Curitiba/Brasil) e especímetro (Golgran ${ }^{\circledast}$, São Caetano do Sul/Brasil.). Após o corte, foram polidos com pedra pomes e taça de borracha, durante 30 segundos, em rotação média. Além disso, cada bloco foi pesado em balança de precisão (Q500L210C Quimis, Diadema/Brasil) antes de passar pelo período experimental. Para que fossem diminuídas possíveis mudanças iônicas entre os blocos e o ambiente bucal, as amostras foram imersas em solução salina por 24 horas

\section{Preparação dos dispositivos de acrílico}

Os 12 voluntários selecionados foram moldados com moldeira plástica e alginato $\left(\right.$ Orthoprint $^{\circledR}$, exportado por Labordental Ltda, São Paulo/Brasil) e sobre os moldes foi vazado gesso especial, tipo IV (Durone ${ }^{\circledR}$, Dentsply,Argentina) sob vibração. Os modelos foram encaminhados para o laboratório de prótese dental (Ideale, Santa Maria/Brasil), para a confecção dos dispositivos de acrílico intra-oral.

Cada dispositivo intra-oral foi feito com resina acrílica autopolimerizável, contendo 4 lojas $(3 \times 3 \times 3 \mathrm{~mm})$, sendo duas de cada lado, na região de pré-molares e de molares, onde foram fixados aleatoriamente os blocos dentais com cera utilidade. Recobriu-se os blocos com uma tela plástica mantendo um espaço de 1milímetro da superfície da amostra, para que não houvesse perturbação mecânica, permitindo o livre acúmulo do biofilme. Essa tela foi fixada com resina acrílica (DuraLay, Pirassununda ${ }^{\circledR}$, São Paulo/Brasil) para identificar claramente onde as soluções deveriam ser gotejadas (Figura 1) ${ }^{12,13}$.

\section{Preparação e análise microbiológica}

Imediatamente após a remoção do dispositivo, foi realizado o deslocamento da tela plástica sobre os blocos de dente, do lado esquerdo, com uma lâmina de bisturi nº15 (Shijiazhuang, China) e o biofilme microbiano, sobre os blocos dentais, foi coletado com um $s w a b$ estéril e imediatamente semeado em três diferentes meios de cultura, Ágar Saburoud, Ágar Sangue e meio cromogênico ${ }^{15}$.

A semeadura do biofilme, em todos os aparelhos, deu-se na mesma ordem: primeiro em Agar sangue, depois em Agar Saburoud e, por último, no meio cromogênico. A seguir, as placas foram incubadas em anaerobiose, a $36^{\circ} \mathrm{C}$, por 24 horas. Após a incubação, foi realizada a análise qualitativa das placas já que era impossível a contagem de unidades formadoras de colônias (UFC). 


\section{Análise do peso mineral}

Após a fase experimental, todos os blocos dentais foram removidos e imersos em água quente, derretendo a cera utilidade que os fixava no aparelho, polidos novamente durante 30 segundos com pedra pomes e taça de borracha, para que não houvesse interferência na nova pesagem. Em balança de precisão, os blocos dentais foram pesados novamente para comparar os novos valores aos obtidos anteriormente, sugerindo-se a perda ou ganho mineral após o experimento.

\section{Análise da microdureza}

Os blocos dentais anteriores, do lado esquerdo de cada aparelho, foram separados para a análise da microdureza, realizada no Laboratório de Materiais Dentários da Universidade Federal do Rio Grande do Sul (UFRGS). Para isso, as doze amostras foram embutidas em suportes plásticos com resina quimicamente ativada, de maneira que houvesse exposição de uma face lateral, para possibilitar o teste de microdureza transversal. Os espécimes foram levados à politriz Aropol 2V (Atrotec, Cotia /Brasil) onde foram polidos, sob refrigeração, com discos de lixa d'água (granulações 600 e 1200 e 2000 da marca 3M, Sumaré/Brasil) durante dois minutos para cada lixa, em velocidade baixa. O polimento final foi feito com disco de feltro e pasta diamantada para polimento universal (Poligloss TDV, Santa Catarina/Brasil) durante um minuto e foram limpos em uma cuba de ultrassônica com água destilada, por 280 segundos, para a remoção de resíduos de cera e pasta ${ }^{11}$.

A microdureza de cada amostra foi avaliada com um penetrador de diamante para dureza Knoop, com carga estática de $25 \mathrm{~g}$ por 5 segundos, em um microdurômetro Shimadzu Micro Hardness Tester (Shimadzu Corporation, Barra Funda/Brasil) acoplado ao Software para análise de imagem CAMS-WIN (NewAge Ind.Estados Unidos da América). O valor da dureza para o esmalte e para a dentina foi estabelecido pela média aritmética de três medidas de cada área ${ }^{11,13}$. Utilizou-se, como controle, quatro blocos que não passaram pela fase intra-oral e tinham o mesmo padrão de peso e dimensões que os demais avaliados.

\section{Análise estatística}

Os dados de dureza e de peso foram testados para sua normalidade pelo teste de Kolmogorv Smirnov. A comparação entre os grupos foi realizada pelo teste de ANOVA e, quando apontou diferenças significantes, foi aplicado o teste de Tukey. Os dados foram analisados no programa SPSS versão 15.0 e o nível de significância estabelecido foi de 5\%. Os blocos de dentes foram tomados como unidade amostral, a fim de conseguir fazer uma comparação estatística entre os grupos.

\section{Resultados}

Os voluntários que participaram do trabalho apresentavam uma média de idade de 22,16 anos. Ao longo do experimento dois indivíduos abandonaram o estudo, um pertencente ao grupo que utilizou a Melaleuca e outro que utilizou a clorexidina, em função de não conseguir se adaptar ao dispositivo de acrílico. Estes sujeitos foram excluídos da análise final.

A tabela 1 apresenta a média do peso, em cada grupo, antes e após a fase experimental.

Tabela 1 - Peso mineral médio, nos diferentes grupos, antes e após o desafio cariogênico e análise estatística entre os grupos

\begin{tabular}{l|r|r|r|r|c}
\hline \multicolumn{1}{c|}{$\begin{array}{c}\text { Grupos } \\
(\mathrm{n} \text { amostras) }\end{array}$} & $\begin{array}{c}\text { Média de peso (g) } \\
\text { antes do experimento }\end{array}$ & $\begin{array}{c}\text { Média de peso (g) } \\
\text { depois do experimento }\end{array}$ & $\begin{array}{c}\text { Diferença } \\
\text { Média }\end{array}$ & $\begin{array}{c}\text { Desvio Padrão } \\
\text { Tukey* }\end{array}$ & $\begin{array}{c}\text { Teste } \\
\text { Tukey* }\end{array}$ \\
\hline Controle (4) & 0,0285 & 0,0285 & - & - \\
Soro Fisiológico (12) & 0,032 & 0,0315 & 0,000500 & 0,00067 & A \\
Clorexidina (8) & 0,03162 & 0,03137 & 0,000250 & 0,00046 & A \\
Melaleuca (8) & 0,03512 & 0,035 & 0,000125 & 0,00035 & AB \\
Própolis (12) & 0,035 & 0,03558 & 0,000583 & 0,00090 & B \\
\hline
\end{tabular}

Legenda: * letras diferentes representam diferença estatística significativa

$\mathrm{Na}$ análise da variação do peso, observou-se que houve uma diferença estatisticamente significante, após o experimento, no grupo da própolis, em relação ao soro fisiológico e a clorexidina $(\mathrm{p}<0,003)$. Esta diferença não foi significativa entre o grupo da própolis e da Melaleuca ( $>0,05$ ). Observou-se que os grupos que utilizaram solução fisiológica, clorexidina $0,12 \%$ e Melaleuca $0,2 \%$ apresentaram peque- na perda de peso mineral, enquanto que o grupo que utilizou própolis $30 \%$ teve um aumento no peso, no período de 14 dias (Tabela 1).

Quanto à dureza Knoop, ou dureza superficial, não houve diferenças estatisticamente significantes entre os grupos, em qualquer zona avaliada (tabela 2 ). 
Tabela 2 - Dureza Knoop em esmalte e dentina, nos diferentes grupos experimentais, e a análise estatística entre os grupos, no esmalte e na dentina

\begin{tabular}{l|r|r}
\hline \multicolumn{1}{c|}{ Grupos (N amostras) } & $\begin{array}{c}\text { Knoop ESMALTE } \\
( \pm \mathrm{DP})\end{array}$ & $\begin{array}{c}\text { Knoop DENTINA } \\
( \pm \mathrm{DP})\end{array}$ \\
\hline $\begin{array}{l}\text { Controle (3) } \\
323,7( \pm 45,86)\end{array}$ & $62,3( \pm 9,82)$ \\
$\begin{array}{l}\text { Soro (9 em esmalte e 6 } \\
\text { em dentina) }\end{array}$ & $355,8( \pm 71,22)$ & $50,7( \pm 8,76)$ \\
Clorexidina (6) & $362,8( \pm 41,65)$ & $50,28( \pm 9,35)$ \\
Melaleuca (6) & $323,3( \pm 61,25)$ & $46,21( \pm 13,34)$ \\
$\begin{array}{l}\text { Própolis (8 em esmalte e } \\
9 \text { em dentina) }\end{array}$ & $337,4( \pm 45,35)$ & $51,26( \pm 9,4)$ \\
ANOVA (p) & $(0,601)$ & $(0,108)$ \\
\hline
\end{tabular}

Em relação à análise microbiológica, observou-se um grande crescimento de bactérias, em 24 horas, nos diferentes meios de cultura e não foi possível realizar a contagem por unidades formadoras de colônias (UFC). Frente a essa análise qualitativa, observou-se, no grupo que utilizou a própolis, um número mais reduzido de colônias bacterianas do que nos outros grupos.

\section{Discussão}

Este trabalho buscou seguir a metodologia in situ, desenvolvida e já utilizada em diversos estudos ${ }^{11,12,13,16,17,18,19}$ buscando padronizar os blocos de dentes em relação ao tamanho e peso, o preparo dos aparelhos de acrílico em um mesmo laboratório, além da determinação dos horários em que os participantes deveriam gotejar as soluções sobre os blocos.

Uma vez que o controle químico com a clorexidina é eficaz no período de 12 em 12 horas ${ }^{20,21}$, as soluções teste também foram utilizadas duas vezes ao dia, no turno da manhã e da noite (de 12 em 12 horas). Para simular o desafio cariogênico diário, a sacarose foi usada 4 vezes ao dia ${ }^{12,21}$ estimulando o crescimento bacteriano nos blocos de dente e favorecendo o processo de desmineralização dos mesmos.

O período experimental foi estabelecido em 14 $\operatorname{dias}^{12,13,19}$, a fim de aumentar o desafio cariogênico e observar uma mudança mais significativa no peso mineral e na dureza, o que não foi observado no trabalho que utilizou apenas 7 dias $^{16}$. Outros trabalhos utilizaram 28 dias ${ }^{11,13}$ como período experimental, mas foi inviável aumentar o experimento pela baixa adesão dos voluntários em seguir os horários adequadamente.

A frequência do uso da sacarose foi estabelecida em 4 vezes ao dia, uma vez que, em 14 dias de desafio cariogênico, já é possível obter um grau de desmineralização do esmalte, em dente, visto clinicamente como mancha branca ativa ${ }^{22,23}$. Cury ${ }^{23}$, seguindo uma metodologia semelhante a esta, mostrou que os blocos de esmalte apresentaram mancha branca visível quando expostos 4 ou 8 vezes por dia ao desafio cariogênico, mesmo em indivíduos com acesso a água fluoretada. Sabe-se que o desequilíbrio no processo de desmineralização e remineralização da estrutura dentária depende dos intervalos entre o controle periódico do biofilme e da frequência da dieta cariogênica, e são esses fatores que levam ao desenvolvimento de uma lesão de cárie incipiente ${ }^{18}$.

Seguindo a metodologia empregada por Silva ${ }^{16}$ em relação ao peso mineral, pode-se observar uma diferença estatisticamente significante no grupo que utilizou à própolis, em relação aos demais, após o período experimental. Observou-se, nos grupos que utilizaram solução fisiológica, clorexidina $0,12 \%$ e Melaleuca $0,2 \%$, uma pequena redução no peso mineral (aproximadamente 30\%) dos blocos. Esta diferença não foi estatisticamente significante, mas pode ter relação com o pouco tempo experimental, devendo ser investigada com um maior número de indivíduos e por um período maior de tempo. Em contrapartida, o grupo que utilizou à própolis $30 \%$, teve um pequeno ganho de peso $(33,33 \%)$ após o período experimental de 14 dias.

Frente aos resultados obtidos sugere-se que a própolis pode evitar a desmineralização dos blocos dentais, avaliada através do ganho de peso mineral $^{11,16}$, quando comparada às outras soluções, as quais não evitaram a perda mineral. Ainda assim, mais estudos são necessários, com amostragem maior e com maior controle na aplicação das substâncias, para se confirmar esta vantagem da solução de própolis.

$\mathrm{Na}$ análise microbiológica, buscou-se seguir a metodologia empregada por Gomes e colaboradores ${ }^{15}$ semeando imediatamente o biofilme coletados dos blocos dentais em três diferentes meios de cultura (Ágar Saburoud, Ágar Sangue e meio cromogênico), incubados em anaerobiose a $36^{\circ} \mathrm{C}$, por 24 horas.

Sabe-se que os meios de cultura aqui utilizados não são os ideais para avaliar o crescimento das espécies cariogênicas (Streptococos do grupo mutans e Lactobacilos) relacionadas ao desenvolvimento da doença cárie, mas foram os únicos possíveis para a realização deste estudo. Os meios Ágar Mitis Salivarius e Ágar SL Rogosa, são os ideais para o crescimento de S. Mutans e de Lactobacilos ${ }^{12,15,24}$, respectivamente.

Após o período experimental observou-se, nos blocos que receberam própolis, um biofilme seco e não aderido ao bloco de esmalte. Acredita-se que com a interferência da própolis no metabolismo bacteriano, possivelmente ocorra uma maior difusão da solução, com ação antimicrobiana e remineralizante, de modo a reequilibrar o processo DESxRE ${ }^{11}$. Este dado deve ser comprovado em outras pesquisas futuramente.

A perda mineral também foi avaliada através da microdureza superficial, em esmalte e em dentina, através de um microdurômetro com carga estática 
de $25 \mathrm{~g} / 5$ segundos, assim como Carli ${ }^{11}$ e Salomão ${ }^{25}$. Enquanto que outros trabalhos observaram a perda mineral pelo método de microscopia com luz polarizada $^{12,13}$.

Quanto à dureza superficial, os resultados obtidos não demonstraram diferenças significantes na dureza Knopp, após o período experimental, com as diferentes substâncias testadas. Entretanto, outros autore ${ }^{11,17}$ encontraram uma diminuição na dureza superficial com a utilização da sacarose, $8 \mathrm{x}$ ao dia, durante 14 ou 28 dias utilizando o mesmo modelo de estudo in situ.

Outro estudo ${ }^{11}$ mostrou que o grupo que utilizou solução de própolis associada ao Fluoreto de Sódio obteve uma significante recuperação da microdureza principalmente nas porções mais superficiais do esmalte. Outros autores ${ }^{26,27}$ também comprovaram a redução da perda mineral pela análise de dureza superficial em espécimes expostas à soluções de própolis.

O estudo in situ apresenta uma grande relevância por simular os eventos ocorridos no ambiente bucal. Desta forma, mais estudos utilizando essa metodologia se fazem necessários para testar substâncias naturais e novas terapias, coadjuvantes ao controle mecânico do biofilme dental, porém com tempo experimental maior e com amostras maiores. Sugere-se, futuramente, que mais estudos utilizem o extrato de própolis como terapia alternativa no controle da atividade cariogênica do biofilme, visto que este produto demonstrou alguma atividade positiva contra os microrganismos cariogênicos.

\section{Conclusão}

- O crescimento bacteriano nos diferentes meios de cultura foi menor no grupo que utilizou a própolis como solução teste, comparado com as demais substâncias.

- No grupo que utilizou própolis houve uma tendência de ganho de peso, após o desafio cariogênico, com diferença significativa para os grupos que utilizaram soro fisiológico e clorexidina, os quais mostraram perda mineral.

- O óleo de Melaleuca não mostrou-se efetivo na inibição da formação do biofilme e teve pouca variabilidade nos níveis minerais, na concentração utilizada.

\section{Abstract}

Objective: to evaluate the effects of natural solutions on biofilm formation and prevention of teeth demineralization. Subjects and method: a pilot study was performed, in situ, with 12 volunteers using removable acrylic devices with four blocks of teeth each. The blocks were subjected to a cariogenic challenge four times a day and tested with an experimental solution twice a day, for 14 days. The sample was divided into four groups with three individuals in each group, testing the following solutions: saline (Group 1), 0.12\% chlorhexidine (Group 2), 0.2\% tea tree oil (Group 3), and 30\% propolis extract (Group 4). At the end of 14 days, the biofilm was collected and seeded in three different culture media. The blocks of teeth were weighed in a precision scale and tested for superficial microhardness. Results: the results showed high microbial growth in all culture media. There was a tendency of mineral weight loss in the blocks of Groups 1, 2, and 3, while Group 4 showed a tendency for weight gain. The microhardness analysis showed a tendency for less dentine strength after the cariogenic challenge in all groups, when compared to the control group that was not subjected to the cariogenic challenge. Conclusion: the $0.2 \%$ tea tree oil had no influence on biofilm formation, superficial microhardness, and block weight, while $30 \%$ propolis extract showed a tendency for interfering with biofilm formation and the mineral weight of teeth.

Keywords: Tea tree oil. Propolis. Dental biofilm. Natural products.

\section{Referências}

1. Castro GD. Diagnóstico das Doenças Cárie e Periodontal. In: Coelho-de-Souza, FH. Fundamentos de Clínica Integral em Odontologia. São Paulo: Editora: Santos; 2009. p.103-112.

2. Petry PC, Toassi RFC. Educação, motivação e controle mecânico do biofilme. In: Coelho-de-Souza FH \& Colaboradores. Tratamentos Clínicos Integrados em Odontologia.1 $1^{\mathrm{a}}$ ed. Rio de Janeiro: Editora Revinter; 2012. p.59-61.

3. Lima JEO. Cárie Dentária: Um novo conceito. Rev. Dental Press Ortodon. Ortop Facial Maringá 2007; 12(6):119-130.

4. Gebran MP, Gebert APO. Controle químico e mecânico de placa bacteriana. Tuiuti: Ciência e Cultura. Curitiba 2002; 26(3): 45-58.

5. Bezerra LMD, Ferreira GLS, Silva ICGS, Castro RD. Atividade Antibacteriana In Vitro de Fitoconstituintes Sobre Micorganismos do Biofilme Dentário. Rev Bras Ciências da Saúde. 2013, 17(1): 79-84.

6. Henz SL, Hilgert LC. Contole químico do biofilme dental. In: Coelho-de-Souza FH \& Colaboradores. Tratamentos Clínicos Integrados em Odontologia. $1^{\mathrm{a}}$ ed. Rio de Janeiro: Editora Revinter; 2012. p 75-83.

7. Lotufo RFM, Lascala Junior NT. Periodontia e Implantodontia: Desmistificando a Ciência. São Paulo. Editora: Artes Médicas Ltda; 2003. p 542.

8. Freire ICM, Pérez ALAL Cardoso AMR, Mariz BALA, Almeida LFD, Cavalcanti YW, et al. Atividade antibacteriana de Óleos Essenciais sobre Streptococcus mutans e Staphylococcus aureus. Rev bras plantas med 2014;16(2) supl. I, 372-377. 
9. Juiz PJL, Alves RJC, Barros TF. Uso de produtos naturais como coadjuvante no tratamento da doença periodontal. Rev Bras Farmacologia. 2010;20:(1):134-139.

10. Machado AC, Oliveira RC. Medicamentos Fitoterápicos na odontologia: evidências e perspectivas sobre o uso da aroeira-do-sertão (Myracrodruon urundeuva Allemão). Rev Bras Pl Med.Campinas, 2014;16(2):283-289.

11. Carli ADD. Ação da própolis de Apis Mellifera associada ao fluoreto de sódio no processo de remineralização de manchas brancas e sobre a microbiota cariogênica: estudo in situ. [periódico na Internet] Campo Grande: Universidade Federal de Mato Grosso do Sul; 2010 [acesso em 15 set. 2015]; Disponível em: http://www.repositorio.cbc.ufms.br.

12. Hara AT, Queiroz CS, Paes Leme AF, Serra MC, Cury JA. Cáries Progression and Inhibition in Human and Bovine Root Dentine in situ. Caries Res 2003;37(5):339-344.

13. Percharki GD, Cury JA, Paes Leme AF, Tabchoury CP, Del Bel Cury AA, Rosalen PL et al. Effect of Sucrose Containing Iron (II) on Dental Biofilm and Enamel Demineralization in situ. Caries Res 2005;39(2): 123- 129.

14. Moriya T, Módena JLP. Assepsia e antissepsia: Técnica de esterilização. Medicina, Ribeirão Preto, 2008; 41(3):265-273.

15. Gomes JEE, Silva RTP, Suguino R, Botelho MPJ. Avaliação microbiológica em diferentes meios de cultura após a remoção do disjuntor de Haas. Maringá - Paraná. [periódico na Internet]. 2011 out. [acesso set. 2015]; Anais eletrônico VII Mostra Internacional de produção. Disponível em: http:// www.cesumar.br.

16. Silva RM, Castro GD. Efeitos do Extrato de Própolis e do óleo de Melaleuca na formação do biofilme e na desmineralização dental: Estudo In Situ. [Trabalho de Conclusão de Curso]. Cachoeira do Sul: Faculdade de Odontologia da Universidade Luterana do Brasil (ULBRA) campus Cachoeira do Sul; 2012.

17. Tenuta LM, Ricomini Filho AP, Del Bel Cury AA, Cury JA. Effect of sucrose on the selection of mutans streptococci and lactobacilli in dental biofilm formed in situ. Cries Res 2006;40(6):546-549.

18. Paes Leme AF, Bellato CM, Bedi G, Del Bel Cury AA, Koo H, Cury JA. Effects of Sucrose on the Extracellular Matrix of Plaque-Like Biofilm Formed in vivo, Studied by Proteomic Analysis Caries Res. 2008;42(6):435-443.

19. Borges MF, Castilho ARF, Pereira CV. Influência da sacarose, lactose e glicose + frutose no potencial cariogênico de S. mutans: estudo in situ e in vitro. Rev.Odonto Ciência 2008;23(4): 360-364.

20. Nogueira MNM, Correia MF, Fontana A, Bedran TBL, Spolidorio DMP. Avaliação Comparativa "In Vivo" da Eficácia do Óleo de Melaleuca, Clorexidina e Listerine sobre Streptococcus mutans e Microrganismos Totais na Saliva. Pesq Bras Odontoped Clin Integr João Pessoa. 2013;13(4):343-349.

21. Zanata FB, Rosing CK. Clorexidina: Mecanismo de ação e evidências atuais de sua eficácia no contexto do biofilme supragengival. Sientific-A 2007;1(2):35-43.

22. Holmen L. Thylstrup A, Gaard B, Kragh F. A Scanning Electron Microscopic Study of Progressive Stages of Enamel Caries in vivo. Caries Res 1985; 19(4):355-367.

23. Cury JA, Rebello MAB, Del Bel Cury AA. In situ Relationship between Sucrose Exposure and the Composition of Dental Plaque. Caries Res 1997;31(5):356-360.

24. Agência Nacional de Vigilância Sanitária (ANVISA). Manual de microbiologia clínica para o controle de infecção relacionada à assistência à saúde. Módulo 4. Descrição dos Meios de Cultura Empregados nos Exames Microbiológicos. Brasília. [periódico na Internet]. 2013 [acesso out. 2015]. Disponível em: http://portal.anvisa.gov.br/.
25. Salomão PMA. Efeito do tipo de lesão cariosa artificial em esmalte bovino sobre o potencial remineralizante as saliva, do dentifrício e do verniz fluoretado: Um estudo in situ. Faculdade de odontologia de Bauru. Universidade de São Paulo. [periódico na Internet]. 2013 Jul. [acesso out. 2015]. Disponível em: http://www.bv.fapesp.br.

26. Giamalia I, Steimberg D, Grobler S, Gedalia I. The effect of própolis exposure on microhardness of human enamel in vitro. Journal Oral Rehabil. 1999; 26(2):941-943.

27. Zárate, PP. Estudo in situ sobre a ação da própolis de Apis mellifera no desenvolvimento da cárie dentária e na formação do biofilme dental. São Paulo. Faculdade de Odontologia da USP. [periódico na Internet]. 2003. [acesso out. 2015]. Disponível em: http://bases.bireme.br

\section{Endereço para correspondência:}

Rosiane Stefanello

Av. Vicente Pigatto, 1244

97220-000 Faxinal do Soturno/RS

Fone: (55) 9614-4223.

Email: stefanellorosiane@gmail.com

Recebido: 13/12/2016. Aceito: 02 /02 / 2017. 